\title{
Amaurosis fugax - delay between symptoms and surgery by specialty
}

Clinical Ophthalmology

17 November 2016

Number of times this article has been viewed

\author{
Pia Kvickström' \\ Bertil Lindblom ${ }^{2,3}$ \\ Göran Bergström ${ }^{4,5}$ \\ Madeleine Zetterberg ${ }^{2,3}$ \\ 'Department of Ophthalmology, \\ Skaraborg Hospital, Skövde, \\ ${ }^{2}$ Department of Clinical \\ Neuroscience/Ophthalmology, \\ Institute of Neuroscience and \\ Physiology, The Sahlgrenska Academy \\ at University of Gothenburg, \\ Gothenburg, ${ }^{3}$ Department of \\ Ophthalmology, Sahlgrenska \\ University Hospital, Mölndal, \\ ${ }^{4}$ Department of Molecular and \\ Clinical Medicine, The Sahlgrenska \\ Academy at University of Gothenburg, \\ ${ }^{5}$ Department of Clinical Physiology, \\ Sahlgrenska University Hospital, \\ Gothenburg, Sweden
}

Purpose: To describe the time course of management of patients with amaurosis fugax and analyze differences in management by different specialties.

Methods: Patients diagnosed with amaurosis fugax and subjected to carotid ultrasound in 2004-2010 at the Sahlgrenska University Hospital, Gothenburg, Sweden ( $n=302)$ were included in this retrospective cohort study, and data were collected from medical records.

Results: The prevalence of significant carotid stenosis was $18.9 \%$, and $14.2 \%$ were subjected to carotid endarterectomy. A trend of longer delay for surgery was noted for patients first consulting a general practitioner $(P=0.069)$ as compared to hospital-based specialties. For $46.3 \%$ of the patients, an ophthalmologist was their first medical contact. No significant difference in time interval to endarterectomy was seen between ophthalmologists and neurologists/internists. Only $31.8 \%$ of the patients with significant carotid stenosis had carotid endarterectomy within 2 weeks from the debut of symptoms, and this proportion was smaller for patients residing outside the Gothenburg city area $(P=0.038)$.

Conclusion: Initially consulting an ophthalmologist does not delay the time to ultrasound or carotid endarterectomy. The overall time from symptoms to surgery is longer than recommended for a majority of the patients, especially for patients from rural areas and for patients initially consulting a general practitioner.

Keywords: amaurosis fugax, carotid endarterectomy, carotid stenosis, carotid ultrasound, transient ischemic attack, transient monocular visual loss

\section{Introduction}

Amaurosis fugax (AF) is a transient monocular visual loss that lasts from seconds to minutes. Uncommonly, the episode may even last for several hours. ${ }^{1}$ The transient monocular visual loss is caused by ischemia in the retina, choroid, or optic nerve. ${ }^{2}$ An embolus from the ipsilateral carotid artery is considered the most common underlying mechanism. ${ }^{3}$ It is not uncommon for patients suffering from transient monocular visual loss, presumably caused by retinal ischemia, to show signs of acute brain infarcts using neuroimaging. ${ }^{4}$ AF patients are therefore at risk of having a cerebral transient ischemic attack (TIA), stroke, or retinal artery occlusion. ${ }^{2}$ AF is viewed as a form of TIA. ${ }^{5}$ Carotid disease, like significant carotid stenosis, is one of the major causes of stroke in the world and stroke itself is one of the most common causes of mortality and severe disability in adults. ${ }^{6}$

Ultrasound (US) of the carotid arteries is usually performed to detect possible significant stenoses of the carotids. If the patient has a significant carotid stenosis, he or she may be eligible for carotid endarterectomy (CEA). This is the most effective stroke prevention in symptomatic patients. ${ }^{7}$ The current recommendation is that the patient should be operated within 2 weeks from the debut of symptoms or even

\footnotetext{
Correspondence: Madeleine Zetterber Department of Clinical Neuroscience/ Ophthalmology, The Sahlgrenska Academy at University of Gothenburg, Sahlgrenska University Hospital, SE-43 I 80 Mölndal, Sweden

Tel +46 31 3433255

Fax +46 3I 412904

Email madeleine.zetterberg@gu.se
} (c) (1) (9) 2016 Kvickström et al. This work is published and licensed by Dove Medical Press Limited. The full terms of this license are available at https://www.dovepress.com/terms.php hereby accept the Terms. Non-commercial uses of the work are permitted without any further permission from Dove Medical Press Limited, provided the work is properly attributed. For permission for commercial use of this work, please see paragraphs 4.2 and 5 of our Terms (https://www.dovepress.com/terms.php). 
within 48 hours if being neurologically stable. ${ }^{6,8}$ However, a recent study shows that the risk of early recurrent stroke in symptomatic carotid stenosis is not as high as was previously feared and data from the Swedish Vascular Registry demonstrate an increased risk of perioperative complications in patients treated surgically within 0-2 days..$^{9,10}$ Whether the risk of CEA in the first 48 hours is increased is however debated. ${ }^{11,12}$

The purpose of this study was to determine the time course of management for patients with $\mathrm{AF}$ and compare the time interval to endarterectomy between specialties.

\section{Materials and methods}

Study patients were identified through the Western Region Initiative to Gather Information on Atherosclerosis database. ${ }^{10}$ The study was approved by the ethical committee at the University of Gothenburg and the tenets of Helsinki were followed. According to the local ethical committee, consent from patients is not necessary in this type of retrospective study. All patients in this study had undergone US between October 1, 2004 and December 31, 2010 at the Sahlgrenska University Hospital (SU) in Gothenburg. They were also given the International Classification of Diseasescode G45.3 (AF) as registered at The National Board of Health and Welfare in Sweden within 6 months prior to the US. This resulted in 387 patients (Figure 1). Patients were included even if the duration of symptoms was atypical for AF as long as they were registered by the G45.3 code. For 16 patients, medical records could not be retrieved and these cases were hence excluded. Patients who had their primary US at SU in Gothenburg, a large city in Sweden with approxi-

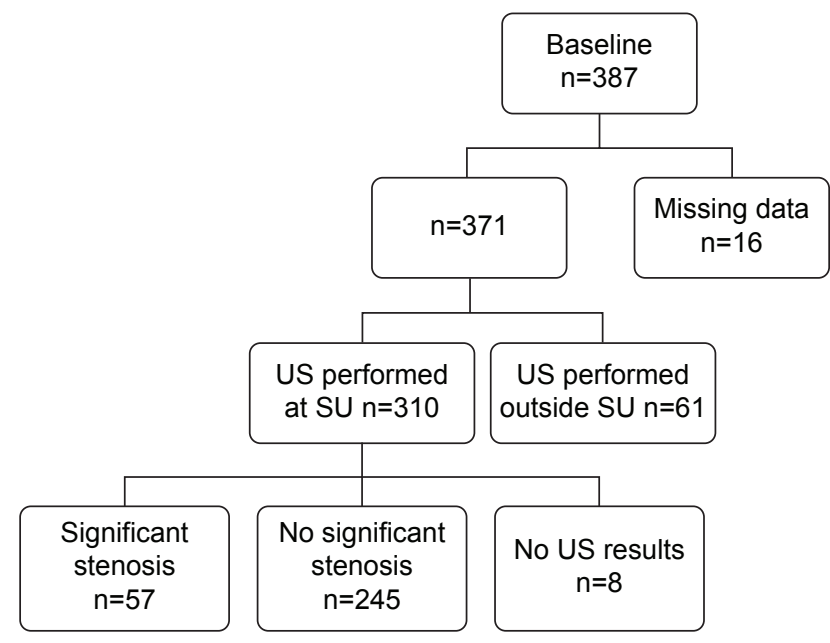

Figure I Inclusion and exclusion of patients subjected to carotid ultrasound (US) due to amaurosis fugax.

Note: Identification/recruitment of study patients with inclusion and exclusion criteria.

Abbreviation: SU, Sahlgrenska University Hospital. mately 550,000 inhabitants in the urban area, were included for comparison of symptom-to-surgery time between specialties. Patients who had their primary US performed at other hospitals in the south-west part of Sweden (ie, Västra Götalandsregionen [VGR]) were referred to SU because of significant carotid stenosis as carotid surgery/CEA during the study period was only performed at SU. The patients from these more rural areas were subjected to a second US at SU for evaluation prior to CEA. This latter patient group was included in a comparison of symptom-to-surgery delay between urban and rural areas but was not part of analyses regarding management by different specialties.

A carotid stenosis of $\geq 70 \%$ was considered significant. All patients with AF and a significant carotid stenosis were subjected to an initial computer tomography of the brain. If the computer tomography of the brain was negative, no additional imaging was performed prior to the CEA. However, if the US was inconclusive, magnetic resonance imaging of the carotids was performed. Data collected from medical records included duration of AF symptoms prior to the first medical contact, the number of doctors, the type of specialties the patients had been in contact with prior to the US, and also the results of the US.

\section{Statistics}

Univariate statistical analysis, Student's $t$-test, Mann-Whitney $U$-test, or Fisher's exact test was used as appropriate. A $P$-value of less than 0.05 was considered statistically significant. SPSS, version 22.0 for Mac (IBM Corporation, Armonk, NY, USA), was used as statistics software.

\section{Results}

In total, 57 (18.9\%) of the 302 patients who had their primary US at SU in Gothenburg and for whom US results could be retrieved had a carotid stenosis of $\geq 70 \%$.

For $46.3 \%$ of all patients, ophthalmology was their first medical consultation. When comparing the proportion of AF patients with significant carotid stenosis between different specialists, general practitioners (GPs) had a higher percentage of patients with carotid disease; $29.6 \%$, compared to other specialists $(14.0 \%, P=0.004)$ (Table 1$)$. The median number of doctors each patient came into contact with prior to the US was 2 (standard deviation 0.9) with no significant difference between patients who were diagnosed with carotid stenosis or not $(P=0.905)$. For patients with a significant carotid stenosis, the time period between first contact with a doctor and the US was significantly shorter, 2 versus 3 days $(P=0.007)$ (Table 2$)$. Regarding the duration between the onset of symptoms and the first contact with a 
Table I Ability of different specialties to predict carotid disease in patients with amaurosis fugax

\begin{tabular}{|c|c|c|c|}
\hline $\begin{array}{l}\text { Type of specialist that the patient } \\
\text { first came into contact with, } n(\%)\end{array}$ & $\begin{array}{l}\text { No significant,* } \\
\text { carotid stenosis, } n=234\end{array}$ & $\begin{array}{l}\text { Significant,* } \\
\text { carotid stenosis, } n=5 \text { I }\end{array}$ & $P$-value \\
\hline Ophthalmologist, $n=132$ (46.3) & $113(85.6)$ & $19(14.4)$ & $0.166^{\S}$ \\
\hline General practitioner, $\mathrm{n}=7 \mathrm{I}$ (24.9) & $50(70.4)$ & $21(29.6)$ & $0.004^{\S}$ \\
\hline $\begin{array}{l}\text { Internist (including cardiologist, } \\
\text { rheumatologist), } \mathrm{n}=60 \text { (2I.I) }\end{array}$ & $52(86.7)$ & $8(13.3)$ & $0.348^{\S}$ \\
\hline Neurologist, $n=14$ (4.9) & $12(85.7)$ & $2(14.3)$ & $1.000^{\S}$ \\
\hline Others, ${ }^{\pi} \mathrm{n}=8$ (2.8) & $7(87.5)$ & I (I2.5) & $1.000^{\S}$ \\
\hline
\end{tabular}

Notes: *A stenosis of the carotid artery was denoted as significant if $\geq 70 \%$. ${ }^{\ddagger} A$ P-value of $<0.010$ was considered significant after Bonferroni correction for multiple comparisons $(n=5)$, ' Fisher's exact test, "Iincluding general surgeons, gynecologists, oncologists, and ear, nose, and throat specialists.

doctor (patient's delay), there were significant differences between patients first consulting a GP as opposed to hospitalbased specialists ( 4 versus 1 day, $P<0.001$ ) and there were also differences in patient's delay between those first seeing an ophthalmologist as compared to an internist or neurologist $(P<0.001)$ (Table 3$)$. The time between US and carotid surgery was significantly longer for patients first contacting a GP as compared to those first seeing a hospital-based specialist (13.5 days compared to 7 days, $P=0.047$ ). The total time between first contact with a doctor to surgery did not differ significantly between those first contacting a GP versus a hospital-based specialist (doctor's delay); median 19 days versus 10 days $(P=0.069)$. For the entire VGR population, the proportion of patients with significant stenosis who underwent CEA within 2 weeks from the debut of symptoms was $31.8 \%$ and $76.1 \%$ were operated within 12 weeks (Table 4 ). Patients from more rural parts of the VGR had significantly longer symptom-to-surgery time than patients residing in the Gothenburg city area $(P=0.038$ for the proportion who had CEA within 2 weeks and $P=0.044$ for proportion who had CEA within 12 weeks).

\section{Discussion}

The most common specialty that the patients first consulted due to AF symptoms was ophthalmology (46.3\%). Previous studies have shown that the number of patients who consult an ophthalmologist because of symptoms related to carotid artery stenosis has increased in recent years. ${ }^{13}$ Most ophthalmologists are regularly exposed to this category of patients; in this study, the majority of the patients $(81.4 \%)$ were examined by an ophthalmologist prior to the US even if it was not their initial consultation.

The prevalence of significant carotid stenosis in this study was $18.9 \%$. This is a fairly high number of patients as $5 \%-12 \%$ of all ischemic stroke is considered caused by carotid stenosis. ${ }^{14,15}$ As studies have shown a lower risk of subsequent stroke in patients with $\mathrm{AF}$ than in those with hemispheric symptoms, the benefit from a CEA procedure is probably lower for AF patients. ${ }^{10,16}$ However, a clear reduction in the 2-year risk of stroke has been demonstrated in AF patients; $6.0 \%$ as compared to $16.6 \%$ with pharmacological treatment only. ${ }^{17}$ In addition, the risk of periprocedural complications (death, stroke, myocardial infarction) of AF patients subjected to CEA is lower than that for patients with preoperative stroke or TIA, something that also argues for surgical intervention in this group. ${ }^{18}$ As a routine, patients with AF symptoms are subjected to a computer tomography scan of the brain at the SU. If this is negative, and the patient does not exhibit additional neuronal symptoms, no further imaging is performed. However, Helenius et al have

Table 2 Time course of management of patients with amaurosis fugax

\begin{tabular}{|c|c|c|c|c|}
\hline $\begin{array}{l}\text { Duration from the onset of symptoms } \\
\text { to first contact with a doctor, (days) }\end{array}$ & $\begin{array}{l}\text { Overall cohort*, } \\
\mathrm{n}=292\end{array}$ & $\begin{array}{l}\text { No significant }{ }^{\ddagger} \text { carotid } \\
\text { stenosis, } n=235\end{array}$ & $\begin{array}{l}\text { Significant }{ }^{\ddagger} \text { carotid } \\
\text { stenosis, } n=49\end{array}$ & $P$-value ${ }^{\S}$ \\
\hline Median (IQR) & I $(0.0-7.0)$ & $\mathrm{I}(0.0-7.0)$ & $2(0.0-12.5)$ & $0.523 \pi$ \\
\hline $\begin{array}{l}\text { Duration from the first contact with a } \\
\text { doctor to ultrasound, (days) }\end{array}$ & $n=296$ & $n=239$ & $n=49$ & \\
\hline Median (IQR) & $3(1.0-10.0)$ & $3(1.0-10.0)$ & $2(1.0-7.0)$ & $0.007^{\pi}$ \\
\hline $\begin{array}{l}\text { Duration from the ultrasound to surgery, } \\
\text { (days) }\end{array}$ & $n=47$ & $\mathrm{n}=0$ & $n=47$ & \\
\hline Median (IQR) & $8(5.0-23.0)$ & 0 & $8(5.0-23.0)$ & NA ${ }^{\pi}$ \\
\hline
\end{tabular}

Notes: *Overall cohort includes patients with unknown US results, ${ }^{\ddagger}$ a stenosis of the carotid artery was denoted as significant if $\geq 70 \%,{ }^{\S}$ a-value of $<0.05$ was considered significant, "Mann-Whitney U-test.

Abbreviations: IQR, interquartile range; NA, not applicable. 
Table 3 Management of patients with amaurosis fugax - time interval to carotid ultrasound and surgery depending on specialty of the first consulted medical doctor

\begin{tabular}{|c|c|c|c|c|c|c|}
\hline $\begin{array}{l}\text { Duration from the debut of } \\
\text { symptoms to first contact with a } \\
\text { doctor, (days) }\end{array}$ & $\begin{array}{l}\text { General } \\
\text { practitioner, } \\
n=65\end{array}$ & $\begin{array}{l}\text { All hospital-based } \\
\text { specialists*, } \\
\mathrm{n}=213\end{array}$ & P-value ${ }^{\S}$ & $\begin{array}{l}\text { Ophthalmologist }{ }^{\&}, \\
n=132\end{array}$ & $\begin{array}{l}\text { Internist or } \\
\text { neurologist, } \\
\mathrm{n}=72\end{array}$ & $P$-value $\S$ \\
\hline Median (IQR) & $4(1-14)$ & I (0-4) & $<0.001 \pi$ & I.5 (0-6) & $0(0-2)$ & $<\left.0.00\right|^{\pi}$ \\
\hline $\begin{array}{l}\text { Duration from the first contact with a } \\
\text { doctor to ultrasound, (days) }\end{array}$ & $\mathrm{n}=66$ & $\mathrm{n}=215$ & & $n=133$ & $n=73$ & \\
\hline Median (IQR) & $5(I-I I)$ & $2(I-8)$ & $0.135^{\pi}$ & $2(I-8)$ & $2(I-5.5)$ & $0.127 \pi$ \\
\hline $\begin{array}{l}\text { Duration from the ultrasound to } \\
\text { surgery, (days) }\end{array}$ & $\mathrm{n}=18$ & $\mathrm{n}=25$ & & $\mathrm{n}=15$ & $n=10$ & \\
\hline Median (IQR) & I $3.5(6.8-43)$ & $7(3-18)$ & $0.047^{\pi}$ & $7(3-20)$ & $5.5(2.8-20)$ & $0.892^{\pi}$ \\
\hline
\end{tabular}

Notes: *Hospital-based specialists included ophthalmologist, internists, neurologists, general surgeons, gynecologists, oncologist, and ear, nose, and throat specialists, \&a $P$-value of $<0.05$ was considered significant, ${ }^{\&}$ the majority of patients initially seen by an ophthalmologist did so in a hospital-based emergency ward, whereas a small number of patients consulted ophthalmologists in private practice, "Mann-Whitney $U$-test.

Abbreviation: IQR, interquartile range.

demonstrated that $24 \%$ of patients with monocular vision loss of presumed ischemic origin had concurrent brain infarct(s) when examined by diffusion-weighted magnetic resonance imaging. ${ }^{4}$ Similarly, Lauda et al detected silent brain infarcts in $23 \%$ of patients with AF or nonarteritic retinal artery occlusions undergoing magnetic resonance imaging within 24 hours after symptom onset. ${ }^{19}$

In this study, only patients who were registered in the medical record with the International Classification of Diseases-code G45.3 and who underwent a carotid US within 6 months were included. One can expect that there were more patients with AF symptoms who did not seek medical help, were not diagnosed as AF, not registered as G45.3, or were not referred for carotid US. In an article by Reid et al, one in six patients ignored the symptoms of AF unless they were recurrent and none of the GPs in that study recommended the patients to seek immediate care at a hospital. ${ }^{20}$ During collection of data in the present study, it was not uncommon to find patients with previous AF attacks, some of whom had even consulted a medical doctor at the time, without subsequent referral for carotid US. This shows that AF is often overlooked as a sign of serious vascular disease

Table 4 Proportion of patients who had carotid endarterectomy within 2 and 12 weeks, respectively, from the onset of symptoms

\begin{tabular}{lllll}
\hline $\begin{array}{l}\text { Carotid } \\
\text { endarterectomy }\end{array}$ & $\begin{array}{l}\text { Overall } \\
\text { cohort }\end{array}$ & $\begin{array}{l}\text { SU } \\
\text { patients* }\end{array}$ & $\begin{array}{l}\text { VGR } \\
\text { patients* }\end{array}$ & P-value $^{\S}$ \\
\hline Within 2 weeks, n (\%) & $28(3 \mathrm{I} .8)$ & $19(43.2)$ & $9(20.5)$ & $0.038^{\ddagger}$ \\
Within 12 weeks, n (\%) & $67(76.1)$ & $38(86.4)$ & $29(65.9)$ & $0.044^{\ddagger}$ \\
\hline
\end{tabular}

Notes: ${ }^{*} \mathrm{SU}$ patients were patients having their first carotid examination at $\mathrm{SU}$ in Gothenburg whereas VGR patients refer to patients who were initially examined with carotid ultrasound at other hospitals in the VGR, sa $P$-value of $<0.05$ was

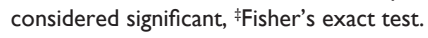

Abbreviations: IQR, interquartile range; SU, Sahlgrenska University Hospital; VGR, Västra Götalandsregion. that could lead to stroke or permanent visual loss, both by patients and doctors. ${ }^{21}$

There was a significantly longer patient's delay, that is, duration between onset of symptoms and the first contact with a doctor, among those who first consulted an ophthalmologist than a neurologist or internist. A plausible explanation is that patients who think that the symptoms are more serious tend to seek a neurologist or an internist at the emergency room rather than an ophthalmologist. The same reasoning can be applied on the difference between hospital-based specialties and GPs. The variation in patient's delay also emphasizes the importance of patient education. Regarding the time interval from first doctor's contact to endarterectomy, that is, doctor's delay, it did not differ between ophthalmologists and neurologists/internists. However, patients first consulting a GP had to wait 5 days (median time) for their carotid US compared to 2 days for patients who first contacted a hospital-based specialty, including ophthalmologists. This difference in waiting time was not significant, probably due to the small numbers $(P=0.135)$. Regarding the time from US to CEA, there was a significant difference in duration between patients first contacting a GP compared to hospital-based specialists with a longer delay for the former $(P=0.047)$. The time from first contact with a doctor to CEA differed between GP and hospital-based specialists with longer delay for patients consulting a GP, but this was not statistically significant $(P=0.069)$, probably because of the small number of patients who underwent CEA in this study. Altogether, this suggests that if possible, as for patients contacting health care counseling by phone for suspect AF, they should be referred to a hospital rather than to the GP office.

A higher proportion of patients who first consulted a GP had a significant stenosis as compared to patients who first contacted hospital-based specialties (29.6\% versus $14.0 \%$, 
$P=0.004)$. One may speculate that hospital-based specialties are more bound to send patients to carotid US and other costly examinations than GPs who are more selective in whom to send. This may explain why GPs had a higher proportion of patients with significant stenosis, something that also implies a risk of missing a number of cases with significant carotid stenosis.

As seen in previous studies, a minority (31.8\%) of patients was subjected to CEA within the recommended 2 weeks and $23.9 \%$ had surgery after 12 weeks, after which the benefit of the operation is considered negligible. ${ }^{21}$ In a study by Vikatmaa et al, only $11 \%$ were operated within 2 weeks and $30 \%$ had surgery after 12 weeks. ${ }^{8}$ Halliday et al presented similar numbers with only $20 \%$ of patients having surgery within 2 weeks and a third after 12 weeks. ${ }^{6}$ A study by den Hartog et al compared the time from the first symptomatic event to surgery over a period of 6 years in which the process of care was partially reorganized. ${ }^{22}$ They showed a marked increase in the proportion of patients who had carotid surgery within 2 weeks from $10.5 \%$ in 2007 to $32.4 \%$ in 2012 . Similar trends have been observed in Gothenburg. ${ }^{10}$ In the present study, we included a comparison of time from symptoms to surgery between patients having their first/primary carotid US at SU and those having their primary carotid US at other hospitals in VGR. Patients who had their primary US at SU usually lived in the Gothenburg metropolitan area, whereas the other patients lived in smaller cities or rural parts of the VGR and were referred to SU for a secondary US and possible CEA. Only $20.5 \%$ of the patients in the secondary US group were operated within 2 weeks from symptoms as compared to $43.2 \%$ of the patients who had their primary US at SU $(P=0.038)$. A limitation of this study is that we do not have data on perioperative events for the present cohort; it would certainly be of interest whether any patients developed a stroke while waiting for their CEA. A previous study on patients with symptomatic carotid stenosis at the SU showed a risk of recurrent stroke of $2.0 \%$ by day 2 , $4.0 \%$ by day 7 , and $7.5 \%$ by day $30 .{ }^{10}$ However, the risk of a recurrent stroke was significantly higher for patients who had a minor stroke as compared to those with a TIA or AF (ocular TIA). Another limitation is that we do not have the actual perioperative event rate for the present cohort of AF patients. However, a study on 2,596 patients recorded in the Swedish Vascular Registry, including patients from our hospital, showed a 30 -day overall rate of $4.8 \%$ for mortality and any stroke, the risk being lowest for those subjected to CEA at days 3-7 (3.6\%). ${ }^{9}$

\section{Conclusion}

In summary, the present study demonstrates differences in delay of management between GPs and hospital-based specialists, something that should be considered when working out recommendations for health care counseling authorities. In addition, the study also demonstrates a difference in time interval to endarterectomy depending on patient residency, which may indicate an inequality in access to care. Finally, this study shows that we are far from the recommended time from symptoms to surgery, urging for an improvement in the management of patients with AF.

\section{Acknowledgments}

This work was supported by grants from the Swedish Research Council (\#2011-3132), Swedish government ("Agreement concerning research and education of doctors"; ALF-GBG-145921), Göteborg Medical Society, Marianne and Marcus Wallenberg Foundation, Dr Reinhard Marcuses Foundation, Konung Gustaf V:s och Drottning Victorias Frimurarestiftelse, Hjalmar Svensson Foundation, Greta Andersson Foundation, Herman Svensson Foundation, Ögonfonden, De Blindas Vänner, and Kronprinsessan Margaretas Arbetsnämnd för Synskadade.

The abstract of this paper was presented at the Nordic Congress of Ophthalmology, Stockholm, Sweden on 20-23 August 2014. The abstract has also been published in the Acta Ophthalmologica Special Issue: Abstracts of the Nordic Congress of Ophthalmology, 20-23 August 2014, Stockholm, Sweden, Volume 92, Issue Supplement s254, pages 1-23, December 2014.

\section{Disclosure}

The authors report no conflicts of interest in this work. The authors alone are responsible for the content and writing of the paper.

\section{References}

1. Group TAFS. Current management of amaurosis fugax. The Amaurosis Fugax Study Group. Stroke. 1990;21(2):201-208.

2. Biousse V, Trobe JD. Transient monocular visual loss. Am J Ophthalmol. 2005;140(4):717-721.

3. Hayreh SS. Acute retinal arterial occlusive disorders. Prog Retin Eye Res. 2011;30(5):359-394

4. Helenius J, Arsava EM, Goldstein JN, et al. Concurrent acute brain infarcts in patients with monocular visual loss. Ann Neurol. 2012; 72(2):286-293.

5. McKibbin M, Verma D. Recurrent amaurosis fugax without haemodynamically significant ipsilateral carotid stenosis. Acta Ophthalmol Scand. 1999;77(2):224-226.

6. Halliday AW, Lees T, Kamugasha D, et al. Waiting times for carotid endarterectomy in UK: observational study. BMJ. 2009;338:b1847. 
7. Kulkarni SR, Gohel MS, Bulbulia RA, Whyman MR, Poskitt KR. The importance of early carotid endarterectomy in symptomatic patients. Ann R Coll Surg Engl. 2009;91(3):210-213.

8. Vikatmaa P, Sairanen T, Lindholm JM, Capraro L, Lepantalo M, Venermo M. Structure of delay in carotid surgery - an observational study. Eur J Vasc Endovasc Surg. 2011;42(3):273-279.

9. Stromberg S, Gelin J, Osterberg T, Bergström GM, Karlström L, Osterberg K; Swedish Vascular Registry (Swedvasc) Steering Committee. Very urgent carotid endarterectomy confers increased procedural risk. Stroke. 2012;43(5):1331-1335.

10. Stromberg S, Nordanstig A, Bentzel T, Osterberg K, Bergstrom GM. Risk of early recurrent stroke in symptomatic carotid stenosis. Eur $J$ Vasc Endovasc Surg. 2015;49(2):137-144.

11. Ferrero E, Ferri M, Viazzo A, et al. A retrospective study on early carotid endarterectomy within 48 hours after transient ischemic attack and stroke in evolution. Ann Vasc Surg. 2014;28(1):227-238.

12. Capoccia L, Sbarigia E, Speziale F, Toni D, Fiorani P. Urgent carotid endarterectomy to prevent recurrence and improve neurologic outcome in mild-to-moderate acute neurologic events. J Vasc Surg. 2011;53(3): 622-627; discussion 627-628.

13. Luo RJ, Liu SR, Li XM, Zhuo YH, Tian Z. Fifty-eight cases of ocular ischemic diseases caused by carotid artery stenosis. Chin Med J (Engl). 2010;123(19):2662-2665.

14. Flaherty ML, Kissela B, Khoury JC, et al. Carotid artery stenosis as a cause of stroke. Neuroepidemiology. 2013;40(1):36-41.
15. Litsky J, Stilp E, Njoh R, Mena-Hurtado C. Management of symptomatic carotid disease in 2014. Curr Cardiol Rep. 2014;16(3):462.

16. Benavente O, Eliasziw M, Streifler JY, et al. Prognosis after transient monocular blindness associated with carotid-artery stenosis. $N$ Engl $J$ Med. 2001;345(15):1084-1090.

17. Barnett HJ, Taylor DW, Eliasziw M, et al. Benefit of carotid endarterectomy in patients with symptomatic moderate or severe stenosis. North American Symptomatic Carotid Endarterectomy Trial Collaborators. N Engl J Med. 1998;339(20):1415-1425.

18. Geraghty PJ, Brothers TE, Gillespie DL, et al. Preoperative symptom type influences the 30-day perioperative outcomes of carotid endarterectomy and carotid stenting in the Society for Vascular Surgery Vascular Registry. J Vasc Surg. 2014;60(3):639-644.

19. Lauda F, Neugebauer H, Reiber L, Juttler E. Acute silent brain infarction in monocular visual loss of ischemic origin. Cerebrovasc Dis. 2015; 40(3-4):151-156.

20. Reid TD, Finney LJ, Hedges AR. The National Stroke Strategy - is it achievable? Ann R Coll Surg Engl. 2009;91(8):641-644.

21. Gladstone DJ, Oh J, Fang J, et al. Urgency of carotid endarterectomy for secondary stroke prevention: results from the Registry of the Canadian Stroke Network. Stroke. 2009;40(8):2776-2782.

22. den Hartog AG, Moll FL, van der Worp HB, Hoff RG, Kappelle LJ, de Borst GJ. Delay to carotid endarterectomy in patients with symptomatic carotid artery stenosis. Eur J Vasc Endovasc Surg. 2014;47(3): 233-239.
Clinical Ophthalmology

\section{Publish your work in this journal}

Clinical Ophthalmology is an international, peer-reviewed journal covering all subspecialties within ophthalmology. Key topics include: Optometry; Visual science; Pharmacology and drug therapy in eye diseases; Basic Sciences; Primary and Secondary eye care; Patient Safety and Quality of Care Improvements. This journal is indexed on Submit your manuscript here: http://www.dovepress.com/clinical-ophthalmology-journal

\section{Dovepress}

PubMed Central and CAS, and is the official journal of The Society of Clinical Ophthalmology (SCO). The manuscript management system is completely online and includes a very quick and fair peer-review system, which is all easy to use. Visit http://www.dovepress.com/ testimonials.php to read real quotes from published authors. 